\title{
İşletme Yönetiminde Kaos Yaklaşımı: Teorik Bir Bakış ${ }^{1}$
}

\author{
DOI: 10.26466/opus.584117 \\ * \\ Muhammet Yüksel* ${ }^{*}$ Yusuf Esmer** \\ * Öğr. Gör., Ondokuz Mayıs Üniversitesi, Terme Meslek Yüksekokulu, Terme/Samsun/ Türkiye \\ E-Posta: muhammet.yuksel@hotmail.com ORCID: 0000-0002-6099-0160 \\ ** Dr. Öğr. Üyesi, Bayburt Üniversitesi, Uygulamalı Bilimler Fakültesi, Bayburt/ Türkiye \\ E-Posta: yesmer@baybirt.edu.tr ORCID: 0000-0003-3691-1730
}

\section{Öz}

Dünyada teknolojide meydana gelen hızh değişim, tüm örgütlerde olduğu gibi işletmelerin örgüt ve yönetim yapılarında da değişime neden olmaktadır. Değişimlerden etkilenmemek neredeyse imkânsız iken bu değişimleri yakalayamamak süreç içerisinde yok olmakla eşdeğer bir durum olarak görülmektedir. Bu değişim ortamında örgütlerin kendilerini olumlu ya da olumsuz etkileyen iç ve dış faktörlere karşı dikkatli olmaları gerekmektedir. Dünyada insanlar için geçerli olan kurallar örgütler içinde geçerli olmaktadır. Bu nedenle örgütler için işlerin her zaman yolunda gitmediğini ve bir karmaşıklığın yaşanabileceğini söylemek mümkündür. Bu karmaşık durumla karşı karşıya kalan örgütlerin karşılaşabilecekleri tüm problemlere karşı hazırlıklı olmaları gerekmektedir. Bu bă̆lamda yöneticilerin kaos odaklı bir yönetim anlayışı benimsemeleri gerekmektedir. Bu çalışmada karmaşık bir durum olarak ifade edilen kaos yaklaşımı işletme yönetimi bağlamında kavramsal olarak incelenmektedir. Bu amaç doğrultusunda çalışmada öncelikle Kaos Teorisi açılanmakta, sonrasında işletme örgüt ve yönetimi açısından kaos yaklaşımı tartışılmaktadır. Bu çalışma işletme yönetimi alanında gelecekte oluşabilecek ilke ve yöntemlerin gelişimine destek vermesi açısından önemlidir.

Anahtar Kelimeler: Kaos, Karmaşıklık, Örgüt, İşletme Yönetimi

\footnotetext{
${ }^{1}$ Bu çalışma 02-04 Mayıs 2019 tarihlerinde Osmaniye' de düzenlenen 18.Uluslararası Iş̧letmecilik Kongresi inde sunulan bildirinin genişletilmiş halidir.
} 


\title{
Chaos Approach in Business Management: A Theoretical Overview
}

\begin{abstract}
The rapid change in technology in the world, as in all organizations, causes change in the organization and management structures of enterprises. While it is almost impossible not to be affected by the changes, not being able to catch these changes is seen as an equivalent situation in the process. In this environment of change, organizations need to be aware of internal and external factors that affect them positively or negatively. Rules applicable to people in the world apply to organizations. For this reason, it is possible to say that things do not always go well for the organizations and a complexity can be experienced. The organizations facing this complex situation must be prepared for all the problems they may face. In this context, managers should adopt a chaos-oriented management approach. The chaos approach, which is expressed as a complex situation in this study, is conceptually examined in the context of business management. For this purpose, the Chaos Theory is first explained in the study and then the chaos approach is discussed in terms of business organization and management. This study is important in terms of supporting the development of future principles and methods in the field of business management.
\end{abstract}

Keywords: Chaos, Complexity, Organization, Business Management 


\section{Giriş}

İş dünyasında evrende olduğu gibi her geçen gün hızlı bir değişim ve gelişim yaşanmaktadır. Bu derece hızlı değişim ve gelişimin yaşandığı iş dünyasında işletme örgütleri için işler her zaman istenildiği gibi yolunda gitmemekte, beklenmeyen karmaşık durumlar yaşanabilmektedir. Karmaşık bir durumun ortaya çıması literatürde kaos olarak adlandırılmaktadır. "Karmaşıklık" olarak ifade edilen "kaos" kavramı ilk olarak fen bilimlerinde incelenmiş ancak daha sonraları sosyal bilimcilerin de dikkatini çekmiş olup, bu konu ile ilgili çok sayıda araştırma yapılmıştır. Kaos kavramı ekonomik açıdan incelendiğinde önceleri ticaret hisselerini geliştirmek için kullanılan bir araç iken daha sonra finansal ve örgütsel konuların birçok alanlarında kullanılan bir kavram haline gelmiştir (Klioutchnikov vd., 2017, s.369). Yunanca Khaos (dipsiz uçurum) sözcügünden gelen kaos, "kargaşa, uyumsuzluk ve karmaşıklık durumu" anlamina gelmektedir (TDK, 2006, s.1). Galacgac ve Singh (2016, s.515) `e göre ise kaos kelimesi söylenince "karışıklık, bozukluk ve kontrol eksikliği akla gelmektedir. Ruelle (1994, s.65) kaosu "başlangiç durumuna hassas bağlılığı bulunan bir zamansal evrim" olarak tarif etmiştir. Bazı araştırmacılara göre kaos, "düzensizlik ve yerini tam olarak bulamama" durumu ile eşdeğer olarak görülmektedir. Oysa kaosun temelinde tesadüf denilen oluşum bulunmadığı gibi, önceden geleceğin tam anlamıly bilinmesi durumu da mümkün olmamaktadır (Töremen, 2000, s.204). Örgütler açısından beklenmedik durumların meydana gelmesi ve bu durumların kaos oluşturması olağandır. Özellikle örgüt yönetimlerinde karşılaşılabilen kaos krizleri çağdaş yönetim yaklaşımları ve kaos teorisi ile açıklanabilmektedir. Kaos Teorisi, örgüt yönetimlerinde değişen şartlarda gücü kendi benliğinde keşfetmekte ve krizleri firsata çevirmeyi hedeflemektedir (Koçel, 2004, s.67).

Bu çalışmada karmaşık bir durum olarak ifade edilen kaos yaklaşımı işletme yönetimi bağlamında kavramsal olarak incelenmektedir. Bu amaç doğrultusunda çalışmada öncelikle Kaos Teorisi açılanmakta, sonrasında işletme organizasyon ve yönetimi açısından kaos yaklaşımı tartışılmaktadır. Çalışma işletme yönetimi alanında gelecekte oluşabilecek ilke ve yöntemlerin gelişimine destek vermesi açısından önemlidir. 


\section{Kaos Teorisi}

Dünya sürekli bir değişim ve gelişim içerisindedir. Özellikle bu değişim ve gelişim belli bir amaç için bir araya gelen örgütleri ve bu örgütlerin yönetim şeklini etkilemiştir. Örgüt yönetim şekilleri ve kuramları sürekli olarak bir değişikliğe uğramıştır. Örgüt ve yönetim kuramları, tarihsel süreç içerisinde Klasik Yaklaşım 'dan Neo-Klasik Yaklaşım ’a ve oradan Sistem Yaklaşımı na ve oradan da Kaos Teorisi ne ve Postmodern yaklaşımlara doğru uzanan bir gelişim ve gelişim anlayışı izlemiştir (Demirtaş, 2006, s.7). Bu değişim ve gelişimler örgütleri daha açık bir sistem haline getirmiştir. Açık sistemlerde bir gerçek olan değişim ile iç içe olan kaos kavramı, birçok kişi ve örgüt için bir tehdit olarak görülürken, bilgi çağında aslında fırsat olarak algılanmalıdır. Değişim ve gelişim kaçınılmazken karmaşayı bir fırsat olarak gören yaklaşım olarak Kaos Teorisi gündeme gelmiştir. Kaos Teorisi ilk olarak 19. yüzyılın sonlarında matematik alanında çalışan Fransız Poincare tarafından yazılan "Bilim ve Yöntemler" adlı eserinde ortaya çıkmıştır. Poincare eserinde dinamik sistemler üzerinde çalışarak dikkatlerden kaçan küçük durumların büyük ve önemli durumlara neden olacağını ve insanların bunu tesadüfi bir durum olarak göreceklerini ifade etmiştir. Küçük farkların büyük farklar oluşturacağını ve bu durumda geleceği öngörmenin mümkün olmadığını savunarak teoriyi şekillendiren ilk bilim adamı olarak literatüre girmiştir (Biçici, 2016, s.30). Levy (1994, s.168) Kaos Teorisi 'ni “karmaşık, doğrusal olmayan, dinamik sistemler" olarak ifade etmektedir. Allen (2001, s.150) ise Kaos Teorisi'ni "çevresine sadece bir yönden değil, çok farklı yönlerden tepki gösterebilme kapasitesine sahip bir sistem "olarak tanımlamaktadır. W. Hehl ve D. Wollschlager Kaos Teorisi 'ni resmetmeye çalışmışlardır. Bu resim Şekil 1`de gösterilmektedir (Murphy, 1996, s.101). 


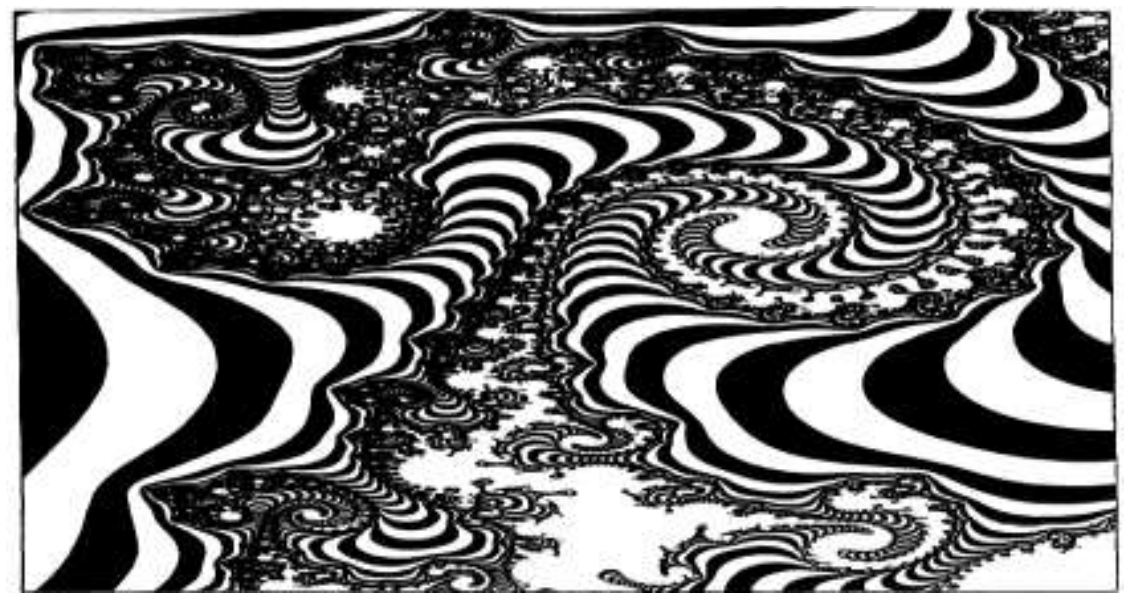

Şekil 1. Kaos Teorisi(Murphy, 1996, s.101)

Kaos Teorisi 'nde önemli bir yer edinen, "kendi kendini örgütleme" teorinin ana unsurlarından biri olmuştur. Kendi kendini örgütleme konusunda ilk çalışmayı Prigoginc yapmıştır (McMillan, 2006, s.26-27). Prigoginc (1987, s.97-99) bu kavramla bizim doğru gördüğümüz sistemlerin doğrusal olmayıp, dinamik yapıda olduklarını belirtmiştir. Bu çalışmalarda daha çok fen bilimleri alanlarında doğanın kanun ve yapısı incelenmiş olmasına rağmen bu çalışmalar sosyal bilimlerle de ilişkilendirilerek bu alanlarda da faydalı olmuştur. Dünya aslında kendi içerisinde her ne kadar karmaşık gözükse de diğer açıdan bir o kadar da basitliği barındırmaktadır. Aynı şekilde işletmelerde iç ve dış etkilere maruz kaldığından karmaşık bir yapıya sahip gibi görünmektedir. Ancak işletmelerde her birimin yetki ve sorumlulukları net ve açık bir şekilde belirlenmiş ve her işletme kendine özgü bir düzen ve yapıya sahip olmaktadir.

Kaos Teori nin en önemli özelliklerinden bir tanesi doğru diye bir sistemin olmaması ve beklenmedik bir durumun olmasıdır. Örgütler bu teoride karışık bir yapı söz konusu olduğundan beklenmedik sonuçlarla karşı karşıya kalabilmektedir. Kaos Teorisi nde küçük gibi görülebilen etkenlerin çok büyük çıktılara dönüşebildiği de görülebilmektedir. Bu durum örgütlerde sitemin çok hassas ve duyarlı bir yapıya sahip olduğunun bir göstergesidir (Marion, 1999, s.13-17). Değişen ve gelişen dünyada zamanın ruhu, iş akışı, bağlantılar, ağlar, sanallaşma, hızlanma gibi 
olayların sonucu olarak Kaos Teorisi göz ardı edemeyeceğimiz bir yaklaşım olarak karşımıza çıkmaktadır (Kıray, 2011, s.282). Kaos Teorisi kendi kendine örgütlenme becerisine sahip olmakla başlamaktadır. Teori iç ve dış etkilerle birlikte örgütlenmede yön alabilmektedir. Bu nedenle bu teori içerisinde bir planlama ya da öngörü yapmak pek mümkün olmamaktadır. Planlamaların ve öngörmelerin yetersiz kaldığ sitem kendinden olağan bir şekilde karar vererek işlemeye devam etmektedir. Klasik yönetimler daha çok sistemi dengeye getirmeye çalışırken, Kaos Teorisi her zaman dengeden uzaklaşma isteğindedir. Değişim her zaman dengeden uzak noktalarda kendi dengesi ile var olmaya devam etmektedir. Dünya değişim ve gelişim gösterdikçe her şeyin olağan gitmesi pek mümkün olmamaktadır. Örgütlerin beklenmeyen bir durum ile karşılaşması karmaşıklık (Kaos) Teorisini ortaya çıkarmaktadır. Rockler (1991, s.56-63) Kaos Teorisi'ni 5 maddede özetlemektedir:

1. Kaos Teorisi, evrenin doğrusal olmayan yönlerini açıklamamıza yardim etmektedir.

2. Kaos Teorisi, Newton Modeli nin indirgemeci yaklaşımı ile kuantum fiziği arasinda bir köprüdür.

3. Kaos Teorisi, sistemin başındaki küçük değiş̧ikliklerin sonunda çok büyük sonuçlara gideceğini göstermektedir.

4. Kaosu anlamanın bir sonucu da evrenin açık sistem olduğunu göstermesidir.

5. Birçok beşeri sistem, en iyi şekilde Kaos Teorisi ile açıklanabilmektedir. Insan vücudunun doğası ve hava tahminleri bunun en son örnekleridir.

Kaos Teorisi 'nin kendine özgü belli bir terminolojisi bulunmaktadır. $\mathrm{Bu}$ tanımlar o kadar iç içe geçmişlerdir ki, bu tanımları anlamadan Kaos Teorisi ni anlamak ve yorumlamak mümkün görünmemektedir. $\mathrm{Bu}$ bağlamda Kaos Teorisi nin özelliğini vurgulamak için Altun (2001, s.455461) birtakım ilkeler belirlemiştir. Bunlar şu şekilde sıralanabilir:

- Doğrusal olmama (birbiri arasında lineer ilişki olmayan-nonlinearity),

- Geribildirim (feedback),

- Çatallanma ve yüzlerin değişimi (bifurcation and face changes),

- Garip çekiciler (strange attractors), 
- Ölçek (scale),

- Fraktallar ve karşıllkları (fractals and correspondance),

- Kendi kendine örgütlenme (self-organization),

- Kendi kendine yenilenme (selfrenewal);

- Başlangıç durumuna duyarlı bağlılık (sensitive dependance on initial condition yada kelebek etkisi (butterfly effect),

- Kaos örüntüleri (chaos pattern),

- Rastgele şoklar (random shocks).

Örgütler açısından kaos kavramında iki önemli nokta söz konusudur. Bunlar iç ve diş faktörlerdir. İç faktörler örgüt ile ilgili faktörler iken, diş faktörler ise örgüt dışında kalan faktörlerdir. Örgütler bilgi çağı olan günümüz çağda beklenmedik iç ve diş faktörlere maruz kalabilmektedir. $\mathrm{Bu}$ faktörler kendiliğinden oluştuğundan, örgütlerinde bu durum karşısında harekete geçmeleri gerekmektedir. Bu karmaşık durumda Kaos Teorisi yeni bir yönetim yaklaşımı olarak ortaya çıkmaktadır (Mason, 2007, s.15-16).

\section{İşletme Örgütlerinde Kaos Yaklaşımı}

İşletme örgütleri yeni dünya düzeninde çevreleri ile sürekli ilişki içerisinde olan açık sistemlerdir. Bu nedenle de faaliyetlerini devam ettirebilmeleri için tıpkı canlılar gibi değişen iç ve dış koşullara ayak uydurmak zorundadırlar. İşletme örgütleri kısa zaman aralıkları ile çok hızlı bir değişiklik gösteren, yarının ne olacağının belli olmadığı ve tahmin edilemediği bir kaosun yaşandığı ortamda önlemler almak zorundadırlar. İşletmelerde kaos, tam olarak işleyen sistemin çıkan pürüzlerle işlenmesinde sorun çıkmasıdır (Wilding, 1998, s.43). Değişimin sürekli bir şekilde var olduğu bilgi çağında, değişime direnmek, örgütler için tehdit oluşturan bir olgudur ve Kaos Teorisi ise değişimin vazgeçilmez bir unsur olduğunu vurgulamaktadır (Sayğan, 2014, s.413). Daha önceleri Klasik Örgüt Teorisi, Neo-Klasik Örgüt Teorisi, Modern Örgüt Teorisi, Post Modern Örgüt Teorisi aşamalardan geçen bilimsel yönetim yaklaşımları son olarak Çağdaş Yönetim Yaklaşımları ile bilgi çağına uygun yönetim arayışlarına girmiş bulunmaktadır (Bayramoğlu, 2016, s.55-57). 21. yüzyıl itibariyle gelişen ve değişen dünyada varlığını en iyi bir şekilde hisset- 
tiren, bilgi ve iletişim teknolojilerindeki gelişmeler ve ilerlemeler, insanlığa verilen değerin eskilere göre kıyaslanamayacak ölçüde artması ve insan sistem bütünleşmesi anlamına gelen bütüncül sistem anlayışının gelişmesi sonucu, kriz yönetiminin ya da karmaşı ortamda yönetimin örgütlerin sistemli bir şekilde işlemesinde insanların fikirlerinin, becerilerinin ve özelliklerinin daha iyi anlaşılmasına imkân verilmesi gerektiği yönündeki anlayış her geçen gün yayılarak gelişmektedir (Koçel, 2004, s.489).

Geçmişte yöneticiler neler yapılacağının bilinmesi ve kendilerinde yeterli kapasitenin olması durumunda yönetimin etkin olarak sağlanacağını düşünmekteydi. Ancak teknolojideki değişiklikler ve yenilikler, büyük ve karmaşık sistemlerin ortaya çıkışı ve toplumun bu yeniliklere çabucak alışarak hızlı bir şekilde adapte olması kriz ve karmaşıklık olasılığını arttırmaktadır (Farazmand, 2003, s.339). Bu kriz ve karmaşık ortama alışık olmayan yöneticiler gerekli yönetim becerilerine sahip olsalar bile hazırlıksız yakalandıkları ilk kaos ortamında ne yapacağını bilmeden yanlış uygulamalarda bulunabilmektedir (Çıraklı vd., 2017, s.335). Kaos Teorisi 'nde her yönetici kendi iç düzeneğini hazırlamakta ve ortaya çıkabilecek her türlü beklenmedik duruma karşı doğal bir tepki vermektedir. Kaos Teorisi nde amaç örgütlerin kendi geleceğini beklenmedik durumlara karşı hazırlamak ve kurtarmaktır. Örgütlerde kaosun var olması aynı zamanda o sistemin yaşadığının ve her zaman var olacağının bir göstergesidir (Ertürk, 2012, s.858-860). Kaos Teorisi'ne göre örgütler içinde bulunduğu dengeden çıarılıp, kaos sınırına geldiğinde, başka bir ifade ile örgütler açısından ani bir beklenmedik durum yaşandığında örgütlerin karşısına yol kavşaklarını andıran çeşitli çıkışlar çıkmakta ve sistem gerek enerjisiyle gerekse karmaşıklık durumlarına hazır olması sayesinde öngörülemez savunmalarla kendi kendini örgütleyerek en az hasarla belki de hiç hasar almadan bu kaostan kurtulmaya çalışmaktadır (Styhre, 2002, s.347-349). Öyle ki bazı örgütler bu kaos ortamın kullanarak bu durumu bir firsat bilmekte ve krizi kendi yararına olacak şekilde değiştirmektedir. Kaos durumunu yaşayan örgüt yöneticisi, örgüt olağan işleyişinde çıkış noktalarını tespit edip, gerektiğinde uygun müdahaleleri yerinde yapmaktadır. Ayrıca yöneticilerin örgütü sürekli karmaşanın sınırında tutması, örgütün sürekli olarak yeni çııı̧ noktaları araması ve hazırda beklemesi, örgütün kendi içindeki potansiyelin 
dışarı çıkmasına yol açmakta, aynı zamanda örgüt çalışanlarının hayal kurma yeteneğini ve üretkenliğini geliştirmektedir (Samur ve İntepeler, 2016, s.171).

Örgütler, istikrar güçlerine ve onları kaosa doğru sürükleyen istikrarsızlık güçlerine maruz kalan doğrusal olmayan dinamik sistemlerdir. Bu bağlamda kaotik bir alanda, örgütlerin kaotik sistemlerin nitel özelliklerini sergileme olasılığı yüksek olmaktadır. Bu özellikler başlangıç koşullarına duyarlılık, değişimin mahremiyeti, özel konfigürasyonlara çekim, farklı ölçeklerde yapısal değişmezlik ve geri dönüşümsüzlük gibi özelliklerdir (Thiétart ve Forgues, 1995, s.19).

Kaos Teorisi örgütlerde uygulandığ 1 için karmaşıklık bilimi olarak bilinmektedir. Kaos Teorisi `ni örgütlerde uygulayabilmek için aşağıdaki ilkelere dikkat etmek gerekmektedir (Englund, 2009, s.1):

- Bilgi birincil örgütlenme kuvvetidir. Bu nedenle bilgi geniş bir şekilde paylaşılmalıdır.

- Farkl ilişkiler geliştirilmelidir.

- Vizyonu görünmez bir alan olarak benimsenmelidir.

- Insanların benzer ihtiyaçları ve buna karşıllk gelen cevapları tespit edilmelidir.

- Birlikte çalışmak bir anlam ve amaç kaynağı olmalıdır.

- Ortak bir amaç duygusu oluşturulmalıdır.

Kaos Teorisi'ni örgütlerde uygulayabilmek için yöneticilerin Kuantum liderlik anlayışı benimsemeleri gerekmektedir. Kuantum liderlik, kuantum düşüncesi ile ortaya çıkmış topluluk temelli bir liderlik yaklaşımıdır. Kuantum liderlik, enerjiyi harekete geçirerek üretkenliğe yönlendiren, kontrole değil, durgunluk ve belirsizliğin oluşturduğu potansiyel duygu ve sezgilere dayalı bir liderlik anlayışıdır (Konan, 2015, s.88). Kuantum liderliğin, liderlik ilişkileri (etkileşim alanı), liderlik etkisinin kaynağı (bilgi, güven, sayg1 ve yüksek beklentiler) ve belirsizlik (kaos) olmak üzere üç boyutu bulunmaktadır. Belirsizlik, Kuantum liderliğin en önemli boyutudur. Çünkü belirsizlik, geleceğin tahmin edilmesinin mümkün olmadığını ifade etmektedir. Kuantum liderler, bu belirsizlik ortamında yol gösterici role sahiptirler (Polat ve Arabac1, 2015, s.217). 


\section{Sonuç ve Öneriler}

Günümüz dünyasında mutlak bir doğruda yaşamak pek mümkün olmamaktadır. Sürekli bir değişim söz konusu olan günümüzde tekdüze bir yaşam, yönetim ya da bilim artık söz konusu olmaktan çıkmaktadır. Bu düzensizlikte ve karmaşıklıkta işletmeler ya da örgütler kendi sistemlerini kurarak potansiyellerinin dışına çıkmakta ve bu şekilde hayatta kalmaya çalışmaktadır. Düzensizlik, karmaşıklık sabit ya da sürekli olan bir şey değildir. Her an değişikliğe uğrayabildiği gibi kendiliğinden veya müdahale sonucu durabilmektedir. Ya da bu durumun aksine aniden ortaya yeniden çıkabilmekte, yerinde ve gerekli müdahaleler yapılmadığ durdurulması çok güç olabilmektedir. Kaos (Karmaşıklık) Teorisi eskiden beri süre gelen örgüt yönetim yaklaşımlarını değişikliğe uğratarak, belli bir birikim sonucu ortaya çıkmış bir yaklaşımdır. Bilgi ve teknoloji çağ 1 olan ve sürekli değişim ve gelişimin yaşandığı bu çağda çok fazla kontrol imkanı olmayan değerli değersiz, küçük büyük birçok verinin kendi içinde bir düzen oluşturduğu anlayışı nedeniyle de teori, çağımız karmaşık örgütleri için ayrıca her an karşılaşabilecekleri kaos durumunda iyi bir değerlendirme ve firsat oluşturma teorisi olarak da değerlendirilebilir. Dolayısıyla kaos işletmeler için bir fırsat olarak görülebilir. Kaos ortamı fırsatlar ve tehditlerden oluşmaktadır. Fırsatları görebilmek ve değerlendirmek ya da tehditleri görebilmek ve önlem alabilmek gerekmektedir. Bu bağlamda işletmeler proaktif bir yönetim yaklaşımı benimsemelidirler.

Kaos olumsuz bir durum olarak görülse de aslında kaos karmaşık bir durumu ifade etmekte ancak her zaman olumsuz bir durumu ifade etmemektedir. Kaos ortamında işletmeler karmaşık durumu iyi analiz etmeli ve bu durumdan yararlı sonuçlar çıkarabilmelidir. Aynı zamanda Kaos Teorisi hiçbir şeyin tesadüfen gerçekleşmediğini mutlaka bir nedeninin olduğunu ortaya koymaktadır. Bu durumda yöneticilerin ortaya çıkan bir problemin mutlaka nedenlerinin olduğunu ve bu nedenlerin küçük ayrıntılarda gizli olduğunu bilmeli ve bu yaklaşımla hareket etmelidirler.

$\mathrm{Bu}$ çalışmada karmaşık ve belirsizlik içeren bir durum olarak ifade edilen kaos yaklaşımı işletme yönetimi bağlamında kavramsal olarak incelenmiş ve tartışılmıştır. Sonuç olarak, yöneticilerin beklenmeyen bir 
durum olarak ifade edilen karmaşıklık ortamında kaos odaklı bir yönetim anlayışı benimsemeleri gerekmektedir. $\mathrm{Bu}$ bağlamda yöneticilerin düzensizlik, belirsizlik ve karmaşıklık ortamında başka bir ifade ile kuantum örgütlerde geçerli olan Kuantum tipi liderlik anlayışı benimsemeleri önerilmektedir (Erçetin vd., 2018, s.112; Gülcan, 2015, s.6). Bu çalışmanın işletme yönetimi alanında gelecekte oluşabilecek ilke ve yöntemlerin gelişimine destek vereceği düşünülmektedir. Bundan sonraki çalışmalarda Kaos Teorisi ve Kuantum liderliğin birlikte ele alınması önerilmektedir. 


\title{
EXTENDED ABSTRACT
}

\section{Chaos Approach in Business Management: A Theoretical Overview \\ Muhammet Yüksel- Yusuf Esmer}

\author{
Ondokuz Mayıs University- Bayburt University
}

There is a rapid change and development day by day in the business world as in universe. In the business world where such rapid change and development is experienced, things are not always going well for business organizations and unexpected complex situations may occur. The emergence of a complex situation is called chaos in the literature. The concept of chaos, which is referred to as complexity, was firstly studied in physical science, but later attracted the attention of social scientists, and many researches were conducted on this subject. When the concept of chaos was analyzed from an economic perspective, it was used as a tool to develop trade shares, but later became a concept used in many fields of financial and organizational issues. It is usual that unexpected situations occur for organizations and these situations create chaos. Especially the chaos crises encountered in organizational management can be explained by contemporary management approaches and chaos theory. Chaos Theory explores the power in its own self under the changing conditions in the management of organizations and aims to turn crises into opportunities (Kocel, 2004, p.67).

Business organizations are open systems in constant relation with their environment in the new world order. Therefore, they must adapt to changing internal and external conditions, just like living things, in order to continue their activities. Business organizations have to take measures in an environment where there is a chaos and tomorrow is unclear and unpredictable. Chaos in businesses, the problem is that the processing of the fully functioning system with the resulting roughness (Wilding, 1998, p.43). Resistance to change is a phenomenon that poses a threat to organizations and Chaos Theory emphasizes that change is an indispensable el- 
ement in the information age in which change is constantly present (Saygan, 2014, p.413). Scientific management approaches that have gone through the stages of Classical Organization Theory, Neo-Classical Organization Theory, Modern Organization Theory and Post Modern Organization Theory have recently entered the searching for management in accordance with the information age with the Contemporary Management Approaches (Bayramoglu, 2016, p.55-57). ). Developments and advances in information and communication technologies that make its presence felt in the developing and changing world by 21st century, the understanding which crisis management and management in complex environment that provide a better understanding of people's ideas, skills, and characteristics in the systematic functioning of organization is developing each passing day as a result of development of integrated system understanding that means human-system integration and increase in the value given to humanity compared the past, and s, (Kocel, 2004, p.489)

Chaos (Complexity) Theory is an approach that has emerged as a result of a certain accumulation by changing the approaches of organization management that have been going on for a long time. The chaos environment consists of opportunities and threats. It is necessary to see and evaluate opportunities or to see threats and take precautions. In this context, enterprises should adopt a proactive management approach.

Although chaos is seen as a negative situation, chaos is a complex situation, but not always a negative one. In a chaos environment, enterprises should analyze the complex situation well and draw useful conclusions from it. At the same time, Chaos Theory reveals that nothing happens by chance, there is a reason. In this case, managers should know that there are reasons for a problem that arises and these reasons are hidden in small details and they should act with this approach.

In this study, chaos approach, which is expressed as a complex and uncertain situation, is examined and discussed conceptually in the context of business management. As a result, managers should adopt a chaos-oriented management approach in an environment of complexity that is expressed as an unexpected situation. In this context, it is recommended that managers adopt a quantum leadership approach which is valid in quantum organizations in the context of disorder, uncertainty and complexity (Ercetin et al., 2018, p.112; Gulcan, 2015, p.6). Quantum leadership is a 
community-based leadership approach that emerged with quantum thinking. Quantum leadership is an understanding of leadership based on the potential emotions and intuitions generated by stagnation and uncertainty, rather than control, and it directs energy to productivity (Konan, 2015, p.88). Quantum leadership has three dimensions: leadership relations (field of interaction), the source of leadership influence (knowledge, trust, respect and high expectations) and uncertainty (chaos). Uncertainty is the most important dimension of Quantum leadership. Because uncertainty implies that it is impossible to predict the future. Quantum leaders have a guiding role in this uncertainty environment (Polat and Arabaci, 2015, p.217). This study is expected to support the development of future principles and methods in the field of business management. In the following studies, it is suggested that Chaos Theory and Quantum Leadership should be handled together.

\section{Kaynakça / References}

Allen, P. M. (2001). A complex systems approach to learning in adaptive networks. Internatonal Journal of Innovation Management, 5(2), 149180. doi:10.1142/S136391960100035X

Altun, S. A. (2001). Kaos ve yönetim. Eğitim Yönetimi Dergisi, 28, 451-469.

Bayramoğlu, G. (2016). Karmaşıklık paradigması ışığında örgüt teorilerinin yeniden değerlendirilmesi. Selçuk Üniversitesi Sosyal Bilimler Enstitüsü Dergisi, 35, 49-63.

Biçici, F. (2016). Kaos teorisi, determinizm ve yeni bilim paradigması sürecinde sosyal bilimler ve turizm araştırmaları açısından önemi. Turizm Akademik Dergisi, 3(1), 29-38.

Çıraklı, Ü., Dalkılıç, S. ve Hacıhasanoğlu, T. (2017). Kaos teorisi, karmaşıklık teorisi, karmaşık uyarlamalı sistemler: Sağlık hizmetleri açısindan bir derleme. International Journal of Academic Value Studies, 3(16), 330-343.

Demirtaş, H. (2006). Yönetim kuram ve yaklaşımları eğitiminin ilköğretim okulu öğretmenlerinin sınıf yönetimi paradigmalarına etkileri. Eğitimde Politika Analizleri ve Stratejik Araştırmalar Dergisi, 1(1), 134. 
Englund, R. L. (2009). Applying Chaos Theory in A Project Based Organization. Global Congress 2009. Amsterdam. 08.04.2019 tarihinde https://www.pmi.org/learning/library/applying-chaos-theoryproject-based-organization-6849 adresinden erişilmiştir.

Erçetin, Ş. Ş., Çevik, M. S. ve Çelik, M. (2018). Okul müdürlerinin kuantum liderlik davranışlarını gerçekleştirme düzeyleri. Uluslararası Liderlik Çalışmaları Dergisi Dergisi: Kuram ve Uygulama, 1(2), 109-124.

Ertürk, A. (2012). Kaos kuramı: Yönetim ve eğitimdeki yansımaları. Kastamonu Ĕ̆itim Dergisi, 20(3), 849-868.

Farazmand, A. (2003). Chaos and transformation theories: A theoretical analysis with implications for organization theory and public management. Public Organization Review: A Global Journal, 3, 339-372.

Galacgac, J. ve Singh, A. (2016). Implications of chaos theory in management science. Chaotic Modeling and Simulation (CMSIM), 4, 515-527.

Gülcan, M. G. (2015). Complexity theory and new leadership paradigm. British Journal of Education, Society \& Behavioural Science, 10(2), 1-12. doi:10.9734/BJESBS/2015/12105

Kıray, A. (2011). Sosyal bilimler karmaşıklık ve kaos. Girişimcilik ve Kalkınma Dergisi, 6(1), 281-286.

Klioutchnikov, I., Sigova, M. ve Beizerov, N. (2017). Chaos theory in finance. Procedia Computer Science, 119, 368-375. doi:10.1016/j.procs.2017.11.196

Koçel, T. (2004). İşletme yöneticiliği. İstanbul: Beta Basım-Yayın-Dağıtım A.Ş.

Konan, N. (2015). Kuantum liderlik. Eğitim Yönetiminde Yeni Liderlik Yaklaşımları içinde (s. 79-108). Ankara: Pegem Akademi.

Levy, D. (1994). Chaos theory and strategy: Theory, application, and managerial implications. Strategic Management Journal, 15, 167-178.

Marion, R. (1999). The edge of organization chaos and complexity theories of formal social systems. California: SAGE Publications, Inc.

Mason, R. B. (2007). The external environment's effect on management and strategy: A complexity theory approach. Management Decision, 45(1), 10-28. doi:10.1108/00251740710718935

McMillan, E. (2006). Complexity, organizations and change: an essential introduction. London and New York: Routledge, Taylor and Francis Group. 
Murphy, P. (1996). Chaos theory as a model for managing issues and crises. Public Relations Review, 22(2), 95-113.

Polat, M., ve Arabacı, İ. B. (2015). Liderliğin kısa tarihi ve açık liderlik. Route Educational and Social Science Journal, 2(1), 207-232.

Prigogine, I. (1987). Exploring complexity. Europcan Journal of Operational Research, 30(2), 97-103. doi:10.1016/0377-2217(87)90085-3

Rockler, M. J. (1991). Thinking about chaos: non-quantitative approach to teacher education. Action in Teacher Education, 12(4), 56-63.

Ruelle, D. (1994). Rastlantı ve kaos. (D. Yurtören, Çev.) Ankara: TÜBİTAK Popüler Bilim Kitapları.

Samur, M., ve İntepeler, Ş. S. (2016). Kaos teorisi ve hemşirelikte kullanım örneği: Bypass cerrahisi. Sağllk ve Hemşirelik Yönetimi Dergisi, 3(3), 169-173. doi:10.5222/SHYD.2016.169

Sayğan, S. (2014). Örgüt biliminde karmaşıklık teorisi. Ege Akademik Bakış Dergisi, 14(3), 413-423.

Styhre, A. (2002). Non-linearin organizations: Organization change management informed by complexity Teory. Leadership and Organization Development Journal, 23(6), 343-351. doi:10.1108/01437730210441300

TDK. (2006). Güncel türkçe sözlük. 25.01.2019 tarihinde http://www.tdk.gov.tr/index.php?option=com_gts\&arama=gts\&guid=TDK.GTS.5c4afa31c97fd0.36272106 adresinden erişilmiştir.

Thiétart, R. A., ve Forgues, B. (1995). Chaos theory and organization. Organization Science, 6(1), 10-31. doi:10.1287/orsc.6.1.19

Töremen, F. (2000). Kaos teorisi ve eğitim yöneticisinin rolü. Kuram ve Uygulamada Ĕ̆itim Yönetimi Dergisi, 6(2), 203-219.

Wilding, R. (1998). Chaos theory: Implications for supply chain management. The International Journal of Logistics Management, 9(1), 43-56.

\section{Kaynakça Bilgisi / Citation Information}

Yüksel, M. ve Esmer, Y. (2019). İşletme yönetiminde kaos yaklaşımı: Teorik bir bakış OPUS-Uluslararası Toplum Araştırmaları Dergisi, 12(18. UiKK Özel Say1s1), 937-952. DOI: 10.26466/opus.584117 